\title{
Estimation of Quality Indicators of Ecological Thermoplastic Fiber Materials
}

\author{
Vladislav SVIATSKII ${ }^{1 *}$, Witold BIALY ${ }^{2}$, Kirill SENTYAKOV ${ }^{1}$ and Alexandr REPKO ${ }^{1}$
}

Authors' affiliations and addresses:

${ }^{1}$ Technology of Mechanical Engineering and Instrument Making, Votkinsk Branch of Kalashnikov Izhevsk State Technical

University, Russia

e-mail: svlad-2000@yandex.ru

e-mail: la1030@mail.ru

e-mail: aleksrepko@gmail.com

${ }^{2}$ Politechnika Śląska, Wydział Organizacji i Zarządzania, Instytut Inżynierii Produkcji

ul. Roosevelta 26, 41-800 Zabrze, Polska e-mail: Witold.Bialy@polsl.pl

${ }^{3}$ Slovak University of Technology in

Bratislava, Faculty of Materials Science and Technology, 91724 Trnava, Slovakia

e-mail: pavol.bozek@stuba.sk

*Correspondence:

Vladislav Sviatskii, Technology of Mechanical Engineering and Instrument Making, Votkinsk Branch of Kalashnikov Izhevsk State Technical University, Russia

e-mail: svlad-2000@yandex.ru

Funding information:

FSBEI

13.04.03/18BBYA

Acknowledgement:

The research is funded by researchers' grant FSBEI of Higher Education "Kalashnikov ISTU" 13.04.03/18BBYA.

How to cite this article:

Sviatskii. V., Bialy, W., Sentyakov, K. and

Repko, A. (2020). Estimation of Quality

Indicators of Ecological Thermoplastic Fiber

Materials. Acta Montanistica Slovaca, Volume 25 (1), 14-23

DOI:

https://doi.org/10.46544/AMS.v25i1.2

\begin{abstract}
The article discusses the process of obtaining fibrous material from a thermoplastic by blowing methods, and also provides a method for calculating the average diameter $d_{f}$ and length $l_{f}$ of elementary fibers. According to the presented calculations, the average elementary fibers' diameter value $d_{f}$ depends on the airflow speed from the blow head in the fiber formation zone. The greater the air velocity $V_{p}$, the smaller the diameter of the elementary fibers. The elementary fibers' length if depends on their diameter $d_{f}$ and variable angle $\gamma$ of the blowing head diffuser. The smaller the diameter of the elementary fibers $d_{f}$ and the larger the variable angle $\gamma$, the smaller the length of the elementary fibers. At $\gamma=0$ degrees, the fiber is obtained, with an increase in the angle $\gamma$, the fiber length becomes fixed. The average elementary fibers' diameter $d_{f}$ varies depending on the speed of the airflow flowing from the blowing head in the fiber formation zone. The greater the air velocity $V_{p}$, the smaller the diameter of the elementary fibers. The discrepancy between the calculating results of the average fiber diameter with their real values does not exceed $13 \%$, which, according to the process complexity, can be considered satisfactory. The elementary fibers' length lf depends on the elementary fibers' diameter $d_{f}$ and a variable angle $\gamma$. The smaller the diameter of the elementary fibers $d_{f}$ and the larger the variable angle $\gamma$, the smaller the length of the elementary fibers. At $\gamma=0 \mathrm{deg}$, the infinite length fiber is obtained, and with an increase in the angle $\gamma$, the fiber length becomes fixed.
\end{abstract}

\section{Keywords}

recycled thermoplastic raw materials; vertical and horizontal method of blowing a melting jet; fiber formation; methodology for calculating the average diameter and length of elementary fibers.

(C) 2020 by the authors. Submitted for possible open access publication under the terms and conditions of the Creative Commons Attribution (CC BY) license (http://creativecommons.org/licenses/by/4.0/). 


\section{Introduction and Basic Information}

Among the promising technologies for the production of the fibrous materials from secondary thermoplastics, one can attribute the blowing method, the essence of which is to inflate the thermoplastic stream jet flowing from the melting unit with a stream of compressed air. In this case, the melting unit can be of any type, for example, hydrostatic or extrusion (Sviatskii et al., 2015; Sviatskii et al., 2018).

The technological process for producing fibrous materials by the blowing method from recycled thermoplastics consists of stages (Fig. 1).

At the first stage, the preparation of feedstock is carried out. Primary or secondary granular PET material, as well as flexes (flakes) obtained after the crushing of used plastic containers, can be used as the raw material for the production of the fibrous materials (Sentyakov et al., 2014; Sentyakov et al., 2016). Judging by the experience of obtaining such products by vertical blowing method, the use of flexes as a feedstock significantly reduces the production cost. The preparation of the feedstock is following: - it is careful sorting because it should exclude the presence of metal or other refractory objects that could lead to an equipment malfunction; raw materials drying in order to remove moisture from it, which can lead to a noticeable decrease in the finished product quality.

Worldwide growth in polymer waste ranges from 5 to $10 \%$ annually. In 2018, according to the European Statistical Agency (Eurostat), polymer waste amounted to almost 30 million tons. In the structure of polymeric wastes, 34\% are polyethylene wastes; $30 \%$ PET; $14 \%$ - PP; $8 \%$ - Polystyrene and other materials. Of the total amount of polymer waste, up to $50 \%$ is plastic packaging, containers made of PET materials [2].

Processing of polymer waste into secondary raw materials, which can be used as a new resource base, is one of the most dynamically developing areas.

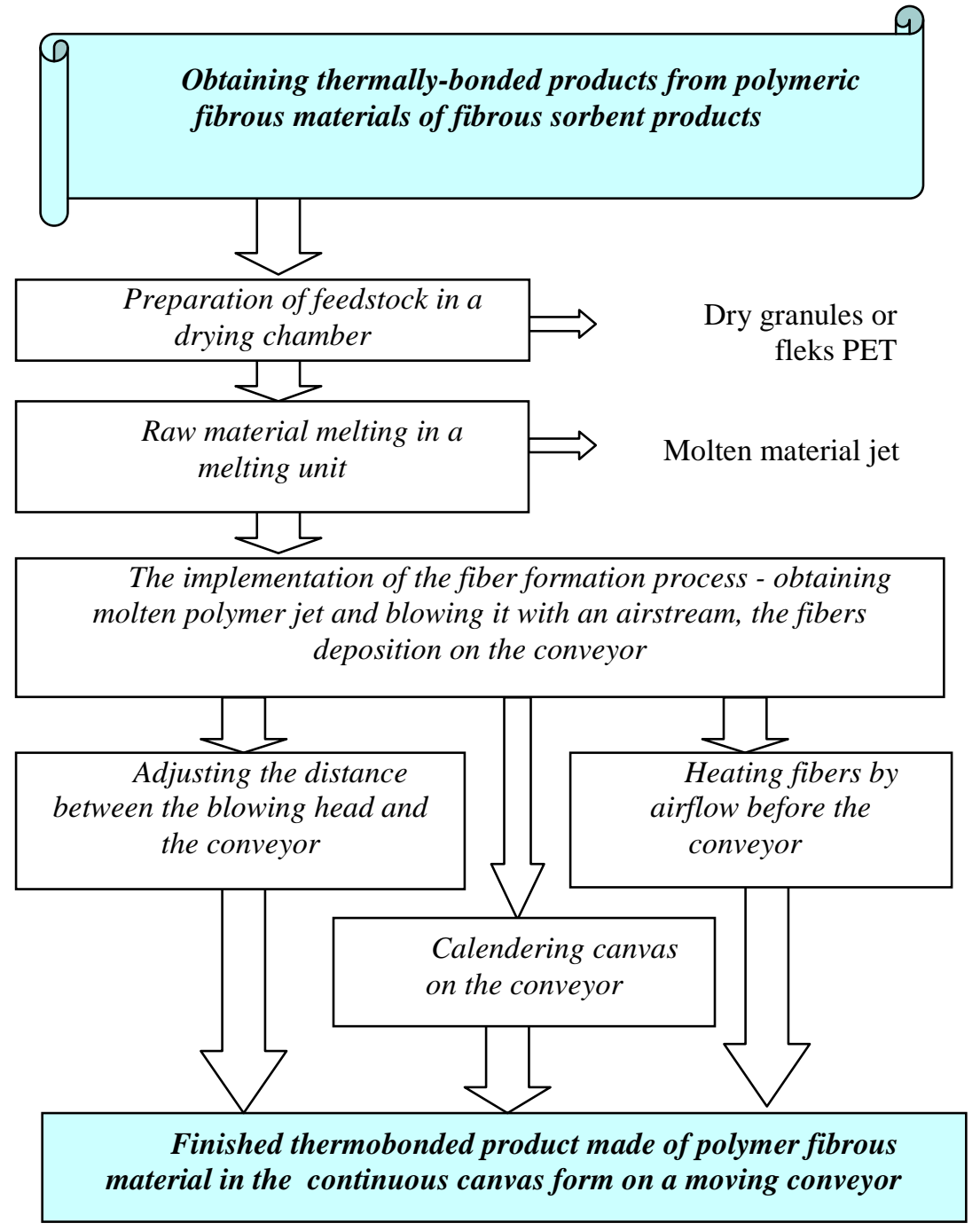

Fig. 1. The technological scheme of obtaining thermally-bonded products from polymeric fibrous materials 


\section{Literature review}

The nomenclature of manufactured structural and building materials is currently quite extensive. A separate place in it is occupied by fibrous materials from mineral and synthetic raw, which are widely used in engineering, construction, heat power, and light industry (Baranov et al., 2017). The use of such materials as various composite materials production basis and as sorbents for environment purification from oil and oil products pollution is promising (Yim et al., 2018).

Of dual interest to the national economy are fibrous materials products based on recycled synthetic raw. The point of such dual interest is that the use of recycled raw materials can significantly reduce the cost of the finished products, and the extraction of such raw materials from the environment can solve one of the environmental problems - to prevent environmental pollution with synthetic household and industrial waste.

Processing of polymer wastes into fibrous materials is difficult due to the lack of an appropriate level of wastes sorting and treatment that are not homogeneous in chemical composition and contain inclusions. In addition, as a rule, the waste has a lower molecular weight compared to standard primary thermoplastic raw materials. As a result, secondary thermoplastics have a lower melt viscosity and melting point, as well as low mechanical characteristics that do not allow the use of classical (spunbond) technologies for the production of the fibrous materials.

\section{Methodology}

In the second stage, it is necessary to meet the feedstock and get a molten material stream with the given parameters: the primary diametrical size and the initial flow rate.

To implement this stage, equipment for processing various plastic materials is used - a screw extruder or a melting unit with the molten material outflow under the influence of hydrostatic pressure in the form of a cylinder with external electric heating elements.

The screw extruder has a complicated shape (Beno et al., 2013; Buransky et al., 2013). At present, it is possible to use modern production technologies such as 5-axis machining (Kovac and Peterka, 2014; Pokorný et al., 2012), CAD/CAM/CNC and IT technology (Nemeth et al., 2019), and modern cutting tools (Peterka and Pokorny, 2014), mostly coated (Chaus et al., 2018), to produce a screw extruder. These technologies ensure a high match of complex shape (Vopat et al., 2014) and dimensional accuracy (Peterka et al., 2008) and satisfactory roughness of the machined surface (Peterka, 2004; Vopat et al., 2015).

In the third stage, it is necessary to implement the fiber formation process, acting on the molten material stream with a compressed air stream, to obtain elementary staple fibers with an average diameter of $10 \ldots 150$ microns and a length of 50 to $500 \mathrm{~mm}$.

At the fourth stage, it is necessary to perform the preliminary formation of a given geometric shape of the product. Regardless of what geometric shape the finished product will have (flat napkins, pillows or sheets), the primary product for their further formation is a canvas. Such a canvas is a non-woven fibrous product in which elementary staple fibers intertwined with each other are held together by natural cohesion forces. In crosssection, the canvas can be made with a thickness of 20 to $100 \mathrm{~mm}$ and a width of 500 to $1200 \mathrm{~mm}$. The canvas is formed during the deposition of elementary staple fibers emerging from the blowing head on the conveyor belt, so its length is not fixed (Smirnov et al., 2018; Kobeticova et al., 2017).

The fifth, final stage of the technological scheme for producing thermally-bonded products involves the thermal treatment of the primary canvas formed from elementary polymer fibers, and as shown in Fig. 1 has three embodiments.

The first option of the final stage is to reduce the distance from the fiberizing device to the receiving conveyor when the elementary fibers moving together with the airflow have not yet entered the solid phase. In this case, the fibers' thermal bonding occurs due to their adhesion to each other. The number of such bonded fibers, the strength, and the conditional density of the resulting product is inversely proportional to the distance indicated above. To ensure the stability of the finished product properties across the conveyor width, it is necessary that the blowing head of the fiberizing device oscillates in the horizontal plane. When implementing this option, it will be necessary to stabilize the surrounding space temperature (Bako and Bozek, 2016).

The second option of the final stage is heating the fibers, for example, with an electric hairdryer to maintain the temperature of the elementary fibers at the beginning of their deposition process on a conveyor close to the melting temperature. When using PET fiber to obtain thermally-bonded products, the airflow temperature acting on the primary canvas should be in the range $220 \ldots 250{ }^{\circ} \mathrm{C}$. In this case, it is necessary to ensure uniform temperature distribution across the canvas width, for example, using several hairdryers placed at the same distance along the nozzle width or one hair dryer that performs transverse vibrations using a special mechanism with an amplitude equal to the width of the canvas.

The third version of the final stage is the calendaring process implementation. In this case, the primary canvas is passed between two cylindrical rollers heated to a temperature close to the polymer melting temperature. In this case, on the canvas surface, it is possible to obtain a thin layer of elementary fibers that are soldered together, increasing the strength of such a thermally bonded product. It is possible to make such an 
option with one calendering roller - in this case, the thermal bonding of the fibers will occur only on one surface of the canvas deposited on the conveyor. Naturally, canvas strength is reduced. However, it becomes possible to use it, for example, for oil products sorption from the surface of the water. Then its conditional density should be less.

\section{Materials and methods}

In the course of research and development work to develop a technology for manufacturing products from fibrous materials based on secondary PET, a block diagram of the machines and assemblies interaction was developed (Fig. 2), which contains two technological machines: M1 - a machine for the production of the fibrous materials based on secondary raw materials with a hydrostatic melting unit type and M2 - a machine for the production of the fibrous materials based on secondary raw materials with an extrusion melting unit type.

In the secondary raw materials preparation, most of the units that make up the M1 and M2 machines are universal - they can be used in other similar machines for processing secondary synthetic raw materials. Such universal aggregates are aggregates for the feedstock preparation: A11 - aggregate for feedstock crushing; A12 unit for drying the source and granular raw materials; A13 - unit for granulating raw materials; A14 - unit for the dosed supply of source and granular raw materials. The functioning of these units is accompanied by the following processes: P11 - the process of secondary raw materials crushing- in the considered technology - used plastic bottles of polyethylene terephthalate with the fleks formation no larger than $5 \mathrm{~mm}$; P12 - the secondary raw materials drying process before granulation, which may be preceded by the process of cleaning the obtained flexes from paper and other foreign inclusions; P13 - the process of granulating raw materials, which is not elementary and includes the processes of melting flexes in an extruder, the formation and cooling of a system of molten raw materials jets with their subsequent crushing and the formation of the granules with a diameter of 1.5 $\ldots 2 \mathrm{~mm}$ and a length of $3.4 \mathrm{~mm}$; P14 - the raw materials (granules) drying process before melting to remove moisture, the presence of which significantly reduces the quality of the finished products (Bozek and Pivarciova, 2013; Bozek and Pokorny, 2014). Note that the presence of the A13 aggregate for granulating the feedstock is not a prerequisite for the operability of the M1 and M2 machines - not granules, but flexes can be used as raw materials. However, the quality of the products can change for the worse due to difficulties in the melt homogenization process.

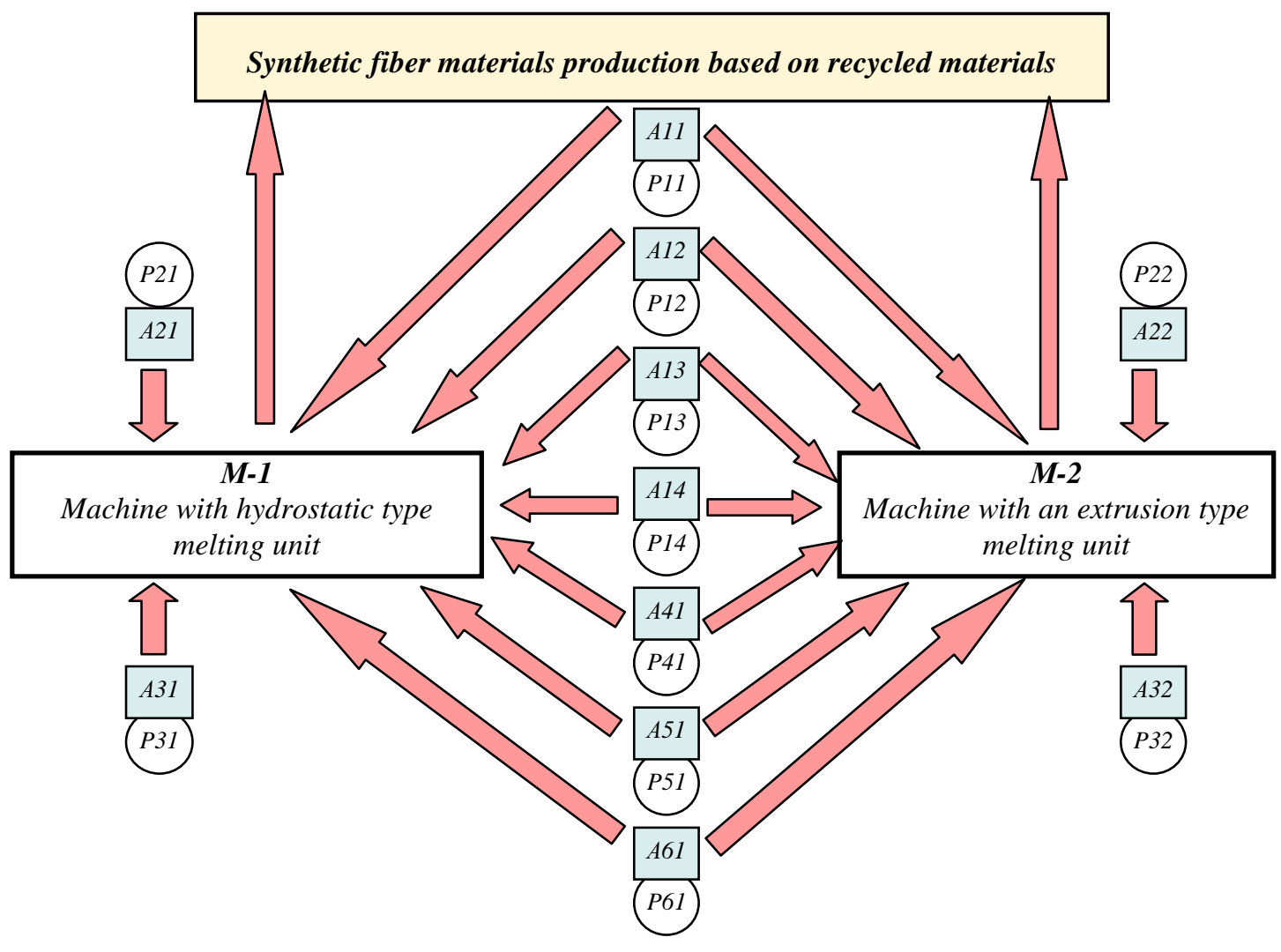

Fig. 2. The structural diagram of machinery and equipment interaction that implements the production of the fibrous materials by blowing from thermoplastics, including secondary ones. 
In the production of the fibrous materials, not all aggregates and the corresponding processes in machines M1 and M2 are completely interchangeable (Yankov, 2006). The main structural difference between the machines M1 and M2 is due to the fact that they use fundamentally different melting units, respectively, in the first - the hydrostatic type melting unit A21, and in the second - the extrusion type melting unit A22. They also differ in jet-forming units: in a machine M1 - a jet-forming unit A31 of vertical design, and in a machine M2 - a jetforming unit A32 of horizontal design. Accordingly, the processes that determine the functioning patterns of these units are different: P21 - the process of melting raw materials in a hydrostatic type melting unit, P22 - the process of melting raw materials in an extruder-type melting unit and P31 - the formation process of molten raw materials jet during vertical flow, P32 - the formation process of molten raw materials jets during the horizontal flow.

The following three machines units under consideration realizing the production of products from fibrous materials based on secondary thermoplastic raw materials are also interchangeable and can be used in similar machines not only developed by the authors M1 and M2, but also in other possible options, these are: A41 and P41 - aggregates and processes fiber formation. A51 and P51 - aggregates and processes of canvas formation. A61 and P61 - aggregates and processes of thermal bonding.

When designing industrial equipment for the fibrous material production from thermoplastics by blowing method, the task is to determine the geometric and energy parameters of the technological process at which the production of fibrous materials with specified quality indicators is provided (Domnina and Repko, 2017). And, first of all, the production of fibrous materials with the required average diameter $d_{f}$ and length $l_{f}$ of elementary fibers.

In the vertical-blowing method (Fig. 3), the process of converting a molten thermoplastic, flowing out of a melting unit under hydrostatic pressure, into a fiber is based on the assumption that the airflow generated in the blowing head with an annular nozzle has a double role: stretching the melt jet due to surface friction forces and its separation. According to the first hypothesis - due to aerodynamic forces in turbulent flow, according to the second hypothesis - due to the surface friction forces. Downstream of the airflow, the further movement of elementary fibers occurs under the influence of turbulent airflow, in which, as a result of cooling the fibers, the temperature decreases below the melting point of the material, and the fiber formation process stops.

In the extrusion-blowing method (Fig. 4), the process of obtaining elementary fibers from thermoplastics during horizontal blowing involves the melting and transportation of the feedstock by extrusion. In this case, the melting stream from the die extends horizontally. Due to gravity, the melting stream assumes a shape curved in the vertical plane and also increases by $15 \ldots 25 \%$ in the transverse direction due to a decrease in the flow velocity, and then, due to the viscous flowing state of the melt, the jet diameter gradually decreases. An air stream flowing out of the blowing head slotted nozzle affects the melting stream in the plastic state zone, deforming it, as a result of which it bends, stretches, and bursts into elementary fibers due to the surface friction forces. Further movement of elementary fibers occurs under the influence of turbulent airflow, as a result of their cooling, the process of fiber formation stops.

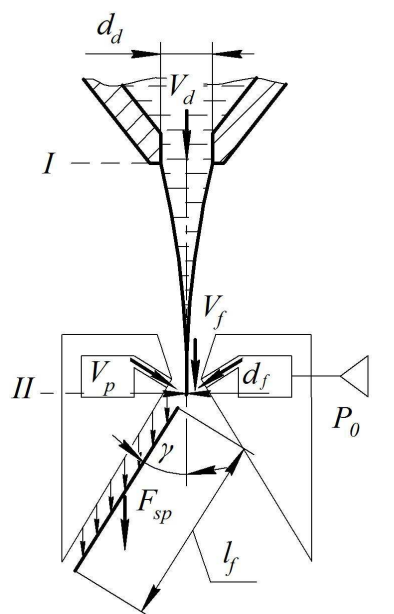

Fig.3. The design scheme for determining the average diameter $d_{f}$ and length $l_{f}$ of elementary fibers for the vertical-blowing method

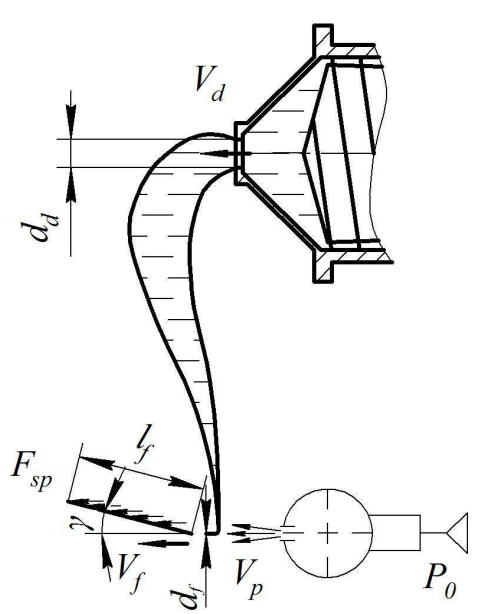

Fig.4. The design scheme for determining the average diameter $d_{f}$ and length $l_{f}$ of elementary fibers for the extrusion-blowing method

A theoretical study of the melt flow process shown in Figures 3 and 4 showed that the nature of the melting flow depends on many factors that affect the quality of the resulting fiber, and is a function:

$$
d_{f}, l_{f}=f\left(V_{d}, V_{p}, V_{f}\right)
$$


where $V_{d}$ is the melt flow speed through the die, $\mathrm{m}^{-1} \mathrm{~s}^{-1}, V_{p}$ - the airflow speed at the blowing head outlet, m.s${ }^{1} ; V_{f}$-the fiber moving speed at the moment of separation, $\mathrm{m} \cdot \mathrm{s}^{-1}$.

The design scheme for producing fibrous material by the vertical blowing of a molten thermoplastic jet flowing out under hydrostatic pressure is shown in Fig. 3. A stream of molten thermoplastic flows out of the melting unit, then this stream enters into interaction with a stream of compressed air flowing out of the blowing head. The diameter of a single filament, which is formed by the interaction of an airstream with a molten material stream, can be determined using the continuity equation:

$$
Q_{I}=Q_{I I}
$$

We determine the volumetric flow rate of the melt jet in sections $I$ and $I I$, where $Q_{I}$ is the flow rate at the die section, and $\mathrm{Q}_{\text {II }}$ is the flow rate in the stretch zone until the jet breaks off by shear.

$$
\begin{aligned}
& Q_{I}=V_{d} \frac{\pi d_{d}^{2}}{4}, \\
& Q_{I I}=V_{f} \frac{\pi d_{f}^{2}}{4},
\end{aligned}
$$

where $V_{d}$ is the melt flow rate through the die, $\mathrm{m} \cdot \mathrm{s}^{-1} ; V_{f}$ - fiber speed at the moment of separation, $\mathrm{m} \cdot \mathrm{s}^{-1} ; d_{d}$ the die diameter, $\mathrm{m} ; d_{f}$ - average diameter of elementary fibers, $\mathrm{m}$.

The fiber velocity at the moment of separation $V_{s p}$ depends on the average speed of the airflow $V_{p}$ flowing out of the blowing head. It can be assumed that the fiber velocity $V_{f}$ will be less than the airflow velocity $V_{p}$; this decrease can be taken into account by the coefficient $K_{t}$.

$$
V_{f}=V_{p} K_{t}
$$

We take the melting jet flow rate in two sections equal to $Q_{I}=Q_{I I}$, and the coefficient $K_{t}<1$ depends on the forces required to burst a solid jet of molten material, as well as on the geometric shape of the blowing head nozzle and the conditions for the formation of the elementary fibers. Then the continuity equation can be written as:

$$
V_{d} \frac{\pi d_{d}^{2}}{4}=V_{P} K_{t} \frac{\pi d_{f}^{2}}{4}
$$

Therefore, from equation (5), one can determine the elementary fiber average diameter:

$$
d_{f}=\sqrt{\frac{V_{d}}{V_{P} K_{t}}} d_{d}
$$

Since the fiber velocity depends on the airflow speed, from the formula (6) we can deduce the coefficient $K_{t}:$

$$
K_{t}=\frac{V_{d} d_{d}^{2}}{V_{p} d_{f}^{2}}
$$

The airflow velocity $V_{p}$ in the elementary fibers formation zone in the blowing head was investigated and determined in workpieces.

The flow rate of the melt from the melting unit $V_{d}$ can be determined by the formula:

$$
V_{d}=\frac{G}{\rho_{p} S}
$$

where $\rho_{p}$ is the molten PET material density, $\left(\rho_{p}=1300 \mathrm{~kg} / \mathrm{m}^{3}\right) \mathrm{S}$ is the die area, which is determined by: $S=\pi d_{f}^{2} / 4, \mathrm{~m}^{3} ; G$ - volumetric capacity of the melting unit, $\mathrm{kg} \cdot \mathrm{s}^{-1}$. The methodology for determining the 
volumetric productivity of a hydrostatic type melting unit is presented in the workpiece (Qazizada and Pivarčiová, 2018).

The results of calculating the coefficient $K_{t}$ are presented in Table 1.

Table 1 - Results of calculating the fiber diameter do and the coefficient $K_{t}$

\begin{tabular}{|c|c|c|c|c|c|c|}
\hline \multicolumn{2}{|c|}{ The blowing head characteristics } & \multicolumn{2}{|c|}{ The melting unit characteristics } & \multicolumn{4}{|c|}{ Characteristics calculation results } \\
\hline \multirow{2}{*}{$\mathrm{P}_{0}, \mathrm{kPa}$} & $\mathrm{V}_{\mathrm{p}}, \mathrm{m} / \mathrm{s}$ & $\mathrm{d}_{\mathrm{d}}, \mathrm{m}$ & $\mathrm{V}_{\mathrm{d}}, \mathrm{m} / \mathrm{s}$ & $\mathrm{d}_{\mathrm{f}}, \mathrm{m}$ & $\mathrm{V}_{\mathrm{f}}, \mathrm{m} / \mathrm{s}$ & 32,4 \\
\hline \multirow{2}{*}{50} & \multirow{2}{*}{81} & 0,0025 & 0,014 & 0,000094 & 32,4 & 0,4 \\
\cline { 3 - 7 } & \multirow{2}{*}{163} & 0,0035 & 0,017 & 0,000140 & 0,4 & 0,90 \\
\hline \multirow{2}{*}{100} & \multirow{2}{*}{258} & 0,0025 & 0,014 & 0,000024 & 144 & 0,90 \\
\cline { 3 - 7 } & & 0,0035 & 0,017 & 0,000038 & 254,8 & 0,98 \\
\cline { 3 - 7 } & & 0,0035 & 0,017 & 0,000028 & 254,8 & 0,98 \\
\hline
\end{tabular}

In addition to pulling the filament from the polymer melt and changing its diameter due to the airflow in the blowing head, there is also a separation force $F_{s p}$, due to which elementary fibers are formed, $H$.

$$
F_{s p}=C_{x} S \frac{\rho_{f} V_{a v}^{2}(\operatorname{tg} \gamma)}{2}
$$

where $C_{x}$ is the thread drag coefficient; $V_{a v}$ - the average airflow rate at the outlet of the blowing head annular gap, m.s ${ }^{-1} ; S$ is the elementary fiber area, $\mathrm{m}^{2}$, which is defined as: $S=d_{f} l_{f} ; \rho_{f}$ - gas density, $\mathrm{kg} / \mathrm{m}^{3} ; \operatorname{tg} \gamma$ is a variable angle that affects the polymer fiber formation along the length lf.

Knowing the separation force $F_{s p}$, we write down the strength conditions of this elementary thread (Elbakian et al., 2018).

According to the first hypothesis, the separation of elementary fibers occurs due to aerodynamic forces in a turbulent flow, where the tensile stress is defined as the ratio of the separation force $F_{s p}$ to the cross-sectional area of the elementary fiber (Kalentev et al., 2017).

$$
\sigma_{p}=\frac{4 F_{s p}}{\pi d_{f}^{2}}
$$

Thus, substituting equation (9) into (10), we obtain the general structure of the formula:

$$
\sigma_{p}=\frac{4 C_{x} l_{f} \rho V_{a v}^{2}(\operatorname{tg} \gamma)}{2 \pi d_{f}} .
$$

At the moment of elementary fibers separation, the tensile stress of the thread must be greater or equal to the allowable stress: $\sigma_{p} \geq\left[\sigma_{p}\right]$. Formula 11 explains how to calculate the elementary fiber length $l_{f}$ :

$$
l_{f}=\frac{\left[\sigma_{p}\right] 2 \pi d_{f}}{4 C_{x} \rho V_{a v}^{2}(\operatorname{tg} \gamma)} .
$$

From formula (12) it follows that the larger the fiber diameter $d_{f}$, the more the fiber length $l_{f}$ increases with an increase in airflow $V_{a v}$ at the exit from the blowing head annular gap.

To determine the fiber length if we take the tensile strength at the time of elementary fibers separation from polyethylene terephthalate $\sigma_{p}=49 \ldots 59 \mathrm{MPa}$; thread drag coefficient $C_{x}=0,026$. In (Elbakian et al., 2018) were investigated seven diffusers designs with an angle $\beta=0 ; 3 ; 5 ; 8 ; 10 ; 12 ; 14 \mathrm{deg}$. 


\section{Results of research}

The calculations results of fiber length lf depending on a variable angle $\gamma$ and fiber diameter $d_{f}$ are presented in Table 2.

From the calculations, it is seen that at an angle $\gamma=0 \mathrm{deg}$. an infinite polymer monofilament is formed, but the larger the angle $\gamma$, the polymer fibers in the process of blowing them with air become of a fixed length $l_{f}$.

As a result of field tests of the fibrous material obtaining process using secondary polyethylene terephthalate, it was shown that when the melt expires with a temperature $t=270 \div 280{ }^{\circ} \mathrm{C}$ through a die with a diameter of $d_{d}$ $=0,0025 \mathrm{~m}$ and airflow affects the resulting monofilament in the blow head working area at $P_{0}=50 \mathrm{kPa}$, fibrous material is formed with an average diameter $d_{f}$ from 0,000080 to $0,000107 \mathrm{~m}$ and a length $l_{f}$ from 0,1 to $0,5 \mathrm{~m}$ at an angle $\gamma=12$ degrees. At $d_{d}=0,0035 \mathrm{~m}$, an angle of $\gamma=12 \mathrm{deg}$ and $P_{0}=50 \mathrm{kPa}$, the average fiber diameter $d_{f}$ was from 0,000097 to $0.000128 \mathrm{~m}$ and a length $l_{f}$ from 0,3 to $0,7 \mathrm{~m}$. After increasing the air pressure in the blowing head to $P_{0}=100 \mathrm{kPa}$, the average fiber diameters at $d_{d}=0,0025 \mathrm{~m}, d_{f}$ from 0,000010 to $0,000027 \mathrm{~m}$; at $d_{d}=0,0035 \mathrm{~m}$, respectively, $d_{f}$ is from 0,000015 to $0,000034 \mathrm{~m}$. In the case of the last two options, the fiber length $l_{f}$ was from 0,004 to $0,1 \mathrm{~m}$ at an angle $\gamma=12$ degrees.

Detailed experimental studies of the blowing head with an annular converging nozzle and the process of fiber formation are presented in workpieces (Straka et al., 2014).

Table 2 - The calculations results of fiber length $l_{f}$

\begin{tabular}{|c|c|c|c|c|c|}
\hline $\mathrm{P}_{0}, \mathrm{kPa}$ & $\mathrm{d}_{\mathrm{f}}, \mathrm{m}$ & $\gamma, \operatorname{deg}$ & Fiber length $\mathrm{l}_{\mathrm{f}}, \mathrm{m}$ & $\mathrm{d}_{\mathrm{f}}, \mathrm{m}$ & Fiber length $1_{\mathrm{f}}, \mathrm{m}$ \\
\hline \multirow{8}{*}{50} & \multirow{8}{*}{$9.4 \times 10^{-5}$} & 0 & Thread goes to $\infty$ & \multirow{8}{*}{$1.4 \times 10^{-4}$} & $\infty$ \\
\hline & & 1 & 1,902 & & 4.101 \\
\hline & & 3 & 0,664 & & 1,374 \\
\hline & & 5 & 0,382 & & 0,821 \\
\hline & & 8 & 0,236 & & 0,506 \\
\hline & & 10 & 0,186 & & 0,406 \\
\hline & & 12 & 0,156 & & 0,336 \\
\hline & & 14 & 0,133 & & 0,281 \\
\hline \multirow{8}{*}{100} & \multirow{8}{*}{$2.4 \times 10^{-5}$} & 0 & $\infty$ & \multirow{8}{*}{$3.8 \times 10^{-5}$} & $\infty$ \\
\hline & & 1 & 0,0319 & & 0,0533 \\
\hline & & 3 & 0,0102 & & 0,0178 \\
\hline & & 5 & 0,0061 & & 0,0106 \\
\hline & & 8 & 0,0038 & & 0,0066 \\
\hline & & 10 & 0,0030 & & 0,0052 \\
\hline & & 12 & 0,0025 & & 0,0043 \\
\hline & & 14 & 0,0021 & & 0,0037 \\
\hline \multirow{8}{*}{150} & \multirow{8}{*}{0.000017} & 0 & $\infty$ & \multirow{8}{*}{0,000028} & $\infty$ \\
\hline & & 1 & 0,0060 & & 0,0166 \\
\hline & & 3 & 0,0021 & & 0,0056 \\
\hline & & 5 & 0,0012 & & 0,0033 \\
\hline & & 8 & 0,00077 & & 0,0021 \\
\hline & & 10 & 0,00061 & & 0,0016 \\
\hline & & 12 & 0,00051 & & 0,0014 \\
\hline & & 14 & 0,00043 & & 0,0012 \\
\hline
\end{tabular}

\section{Conclusion}

Despite its low efficiency (compared to material and raw material recycling), the energy recovery of plastic waste is the only suitable recovery method for highly contaminated plastic packaging (agriculture, construction) and for hardly separable plastic waste (multilayer plastic packaging and foils) (Zhang et al., 2014). For the second potential group of plastic waste, for worn tires, the possibilities of material recycling are limited due to their volume. For example, in the US, there is about $10 \mathrm{~kg}$ of used tires per capita every year; in the EU, it is about $7 \mathrm{~kg}$. Advantages of energy recycling compared to material recycling: 
Waste reduction up to $90 \%$

harmful substances reduction (controlled detoxification)

the possibility of further use of inorganic fractions

Possibility of recovery of contaminated and heavily contaminated plastic waste

the possibility of effective recovery of waste that cannot be recovered through a material or raw material recycling.

The choice of the best plastic waste recycling process depends on several factors. In addition to material characteristics (chemical composition, degree of contamination, the content of inorganic impurities, degree of degradation) and economic indicators (costs of removal, identification, cleaning, sorting), the possibilities of their further application in practice and the environmental impact must be carefully considered.

Thus, the above structural diagram of the technological complex for machines and units interaction that implements the double principle of producing fibrous materials from thermoplastics, which allows solving the problems of their improvement and creating new designs taking into account the peculiarities of the functioning of these processes, and the synthesis of new machines for this purpose (Molenda, 2019).

Also, the article presents methods for calculating the average diameter $d_{f}$ and length $l_{f}$ of the fiber when producing fibrous materials by the vertical-blowing method.

\section{References}

Bako B., Bozek P.: Trends in Simulation and Planning of Manufacturing Companies. ICMEM 2016, Procedia Engineering, Volume: 149, pp. 571-575.

Baranov M., Bozek P., Prajova V., Ivanova T., Novokshonov D., Korshunov A.: Constructing and calculating of multistage sucker rod string according to reduced stress. Acta Montanistica Slovaca. 2017, Vol. 22, Issue: 2, pp. 107-115.

Beno M., Zvoncan M., Kovac M. Peterka, J.: Circular interpolation and positioning accuracy deviation measurement on five axis machine tools with different structures. In Tehnicki vjesnik-technical gazette. Vol 20 Rel 3, pp 479-484, 2013.

Bozek P., Pivarciova E.: Flexible manufacturing system with automatic control of product quality. In Strojarstvo, Volume 55, Issue 3, April 2013, pp. 211-221.

Bozek P., Pokorný P.: Analysis and evaluation of differences dimensional products of production system. In Applied Mechanics and Materials, Volume 611, 2014, pp. 339-345.

Buransky, I., Morovic, L., Peterka, J. Application of Reverse Engineering for Redesigning and Manufacturing of a Printer Spare Part. Conference: 4th International Conference on Manufacturing Science and Engineering (ICMSE 2013) Location: Dalian, PEOPLES R CHINA Date: MAR 30-31, 2013 Sponsor(s): NE Univ; Harbin Inst Technol; Jilin Univ. MATERIAL DESIGN, PROCESSING AND APPLICATIONS, PARTS 1-4 Book Series: Advanced Materials Research. Published: 2013. Vol 690-693, pp. 2708-2712.

Chaus, A.S., Pokorny, P., Caplovic, E., Sitkevich. MV., Peterka, J.: Complex fine-scale diffusion coating formed at low temperature on high-speed steel substrate. In 2nd International Conference on Applied Surface Science (ICASS) Location: Dalian, PEOPLES R CHINA Date: JUN 12-15, 2017. APPLIED SURFACE SCIENCE. Published: 2018. Vol 437, pp. 257-270.

Domnina K., Repko V.: About the application of computational experiment in the theory of fibro-foam concrete. Bulletin of BSTU. V.G. Shukhov. No.10, 2017, pp. 90-93.

Elbakian A., Sentyakov B., Božek P., Kuric I., Sentyakov K.: Automated Separation of Basalt Fiber and Other Earth Resources by the Means of Acoustic Vibrations. Acta Montanistica Slovaca. Vol. 23, No 3, 2018, pp. 271-281.

Environ. Sci. Technol, 46, 2012, pp. 6431-6437.

Kalentev E., Václav S., Božek P., Korshun;ov A., Tarasov V.: Numerical analysis of the stress-strain state of a rope strand with linear contact under tension and torsion loading conditions. In Advances in Science and Technology Research Journal. Vol. 11, Issue 2, pp. 231-239.

Kobeticova H., Sviatskii, V., Gerulová, K., Wachter, I., Nikitin, Y., Blinová, L. Soldán, M.: The use of waste from bauxite ore in sorption of 3,5-dichlorophenol from waste water. Acta Montanistica Slovaca, Vol. 22, No 4, 2017 pp. 404-411.

Kovac, M. Peterka, J.: Selected 5-axis Strategies for High-speed milling of Thin-walled Parts. In International Conference on Materials Science and Mechanical Engineering (ICMSME 2013) Location: Kuala Lumpur, MALAYSIA Date: OCT 27-28, 2013. MATERIALS SCIENCE AND MECHANICAL ENGINEERING Book Series: Applied Mechanics and Materials. 2014. Vol 467, pp. 466-469.

Molenda M.: Quality Study and Improvement of Logistic Processes on the Example of a Chosen Enterprise. Management Systems in Production Engineering, Volume 27: Issue 1, Published online: 28 Mar 2019, pp. $18-22$. 
Nemeth, M., Nemethova, A., Michalconok, G.: Determination Issues of Data Mining Process of Failures in the Production Systems. In 8th Computer Science On-Line Conference (CSOC) Location: CZECH REPUBLIC Date: APR 24-27, 2019. ARTIFICIAL INTELLIGENCE METHODS IN INTELLIGENT ALGORITHMS Book Series: Advances in Intelligent Systems and Computing. 2019. Vol 985, pp. 200207.

Papkov S.: Theoretical foundations of the production of chemical fi bers. Moscow: Chemistry, 1988, 272 pp.

Qazizada E Pivarčiová E.: Reliability of parallel and serial centrifugal pumps for dewatering in mining process. Acta Montanistica Slovaca, Vol. 23, No 2, 2018 pp. 141-152.

Peterka J.: A new approach to calculating the arithmetical mean deviation of a profile during copy milling. In Strojniski vestnik-journal of mechanical engineering. 2004. Vol 50 Rel 12, pp. 594-597.

Peterka, J., Pokorny, P., Vaclav, S.: CAM strategies and surface accuracy. In Annals of DAAAM and Proceedings of the International DAAAM Symposium2008. Annals of DAAAM for 2008 and 19th International DAAAM Symposium", "Intelligent Manufacturing and Automation: Focus on Next Generation of Intelligent Systems and Solutions"; Trnava; Slovakia; 22 October 2008 through 25 October 2008; Code 106299. pp.1061-1062.

Peterka, J., Pokorný, P.: Influence of lead angle from the vertical axis milling on effective radius of the cutter. In Key Engineering Materials. 7th International Congress of Precision Machining, ICPM 2013; Miskolc; Hungary; 3 October 2013 through 5 October 2013; Code 103401. Vol 581, 2014, pp. 44-49.

Pokorný P., Peterka J., Vaclav S., The task of 5-axis milling. In Tehnicki vjesnik-technical gazette. Vol 19, Rel 1 , pp 147-150, 2012.

Sentyakov B., Shirobokov K., Sviatskii V.: Processes of obtaining and practical use of polyethylene terephthalate fiber from secondary raw materials. Stary Oskol: Publishing house «TNT», 2014, $162 \mathrm{pp}$.

Sentyakov B., Repko A., Sviatskii M., Soldan M., Nikitin Y.: Simulation of oil products separation from fibrous sorbent material centrifugally. Acta Montanistica Slovaca, Vol.21(2016), No 3, pp. 238-246.

Straka M., Bindzár P., Kaduková A.: Utilization of the multicriteria decision-making methods for the needs of mining industry. Acta Montanistica Slovaca, 2014, 19(4). pp. 199-206.

Sviatskii V., Sentyakov B., Sviatskii M., Sentyakov K., Garayev S.: Simulation of the process of fabrication canvas with fibrous materials. In Vestnik ISTU, No. 2, Izhevsk, 2015, pp.17-20.

Sviatskii V., Božek P., Sokolov M.: Determination of melting unit productivity when producing synthetic fibrous materials by vertical blowing method. Acta Technologica Agriculturalurae. Vol. 21, No 4, 2018, pp 139-143.

Sviatskii V., Sentyakov B., Sviatskii M., Sentyakov K., Garayev S.: Simulation of the process of fabrication canvas with fibrous materials. Vestnik ISTU, No. 2., Izhevsk 2015, 2015, pp.17-20.

Smirnov V., Repko A.: Workpiece Temperature Variations During Flat Peripheral Grinding. Management Systems in Production Engineering, Volume 26: Issue 2, Published online: 22 May 2018, pp. 93-98.

Vopat T., Peterka J., Kovac M., Buransky I.: The wear measurement process of ball nose end mill in the copy milling operations. 24th DAAAM International Symposium on Intelligent Manufacturing and Automation; Zadar; Croatia; 23 October 2013 through 26 October 2013; Code 104678 Volume 69, 2014, Pages 1038-10472013

Vopat T., Peterka J., Šimna V.: The influence of different types of copy milling on the surface roughness and tool life of end mills. In 25th DAAAM international symposium on intelligent manufacturing and automation, 2014. procedia engineering Vol 100, pp 868-876, 2015

Yankov V.: Processing of fiber-forming polymers." Moscow-Izhevsk: Research Center "Regular and chaotic dynamics. 2006. $452 \mathrm{pp}$.

Yim U., Kim M., Ha S., Kim S., Shim W.: Oil Spill Environmental Forensics: the Hebei Spirit Oil Spill Case, 2018, pp.145- 168 .

Zhang S., Wang P., Fu X., Chung, T.: Sustainable water recovery from oily wastewater via forward osmosismembrane distillation (FO-MD), Water Res., 52, 2014, pp. 112-121. 